\title{
Farmers' mobilisation of social capital for beneficial uptake of technological innovations in southwest Nigeria
}

\author{
Oluwaseun Kolade* \\ Faculty of Arts and Human Sciences, \\ Weeks Centre for Social and Policy Research, \\ London South Bank University, \\ 103 Borough Road, SE1 0AA, London \\ E-mail: koladeo@lsbu.ac.uk \\ *Corresponding author
}

\section{Trudy Harpham}

Faculty of Arts and Human Sciences, London South Bank University, 103 Borough Road, SE1 0AA, London

E-mail: t.harpham@lsbu.ac.uk

\begin{abstract}
Social capital has been identified as an important factor influencing successful uptake of technological innovations among small-scale, rural farmers in developing countries. This study draws on descriptive statistics and regression analysis of data obtained from 325 farmers in southwest Nigeria to examine the effectiveness of social capital mobilised by rural farmers. The results indicate farmers' cooperatives are, because of their stronger organisational capacity and formal structure, able to generate more effective social capital for information sharing and linking up with important external organisations providing technical and financial support for successful adoption of innovations.
\end{abstract}

Keywords: social capital; technological innovations; cooperatives; agricultural production; Nigeria.

Reference to this paper should be made as follows: Kolade, O. and Harpham, T. (xxxx) 'Farmers' mobilisation of social capital for beneficial uptake of technological innovations in southwest Nigeria', Int. J. Technological Learning, Innovation and Development, Vol. X, No. Y, pp.xxx-xxx.

Biographical notes: Oluwaseun Kolade holds BSc and MSc degrees in Civil Engineering from the University of Ibadan, Nigeria, a post-graduate teaching certificate in Higher Education from University College London, and a $\mathrm{PhD}$ in International Development from the London South Bank University. He is a Fellow of the UK Higher Education Academy and a member of Development Studies Association, UK. His research interests include sustainable development, environmental economics, rural and food poverty, innovation systems, and institutional reforms. He is currently a Visiting Fellow at the Weeks Centre for Social and Policy Research, London South Bank University. 
Trudy Harpham is a Professor of Urban Policy and Development at the London South Bank University and an Honorary Professor at the London School of Hygiene and Tropical Medicine, UK. She specialises in urbanisation in developing countries and its impact on well-being, and her research interests also include complementary use of quantitative and qualitative methods, project appraisal and house-hold survey methods. She has over 100 journal publications, has produced five books and has studied urban policy development, and the environmental and social determinants of health in Sub-Saharan Africa, Asia and Latin America. She has supervised over $30 \mathrm{PhD}$ students and received the 2010 International Society of Urban Health Humanitarian Award.

This paper is a revised and expanded version of a paper entitled [title] presented at [name, location and date of conference].

\section{Introduction}

Social capital has been defined as "the sum of the resources, actual or virtual, that accrue to an individual or a group by virtue of possessing a durable network of more or less institutionalized relationships of mutual acquaintance and recognition” [Bourdieu and Wacquant, (1992), p.119]. It is classified into bonding social capital, bridging social capital, and linking social capital. It is measured mainly by 'trust in other people' (Aldridge et al., 2002). Social capital is one of the key parameters explored in discussions about the rate and speed of diffusion of innovations (Rogers, 1995; Deroian, 2002; Valente and Davis, 1999). It is generally acknowledged that, in addition to the engineering process required for the design of innovations and the role of markets, social capital, with its unique emphasis on relational rather than technical tools, constitute a crucial, if intangible, ingredient in the success of innovations (Landry et al., 2002).

In previous studies of agricultural production and diffusion of innovations in Nigeria, whereas there have been references to the importance of collective participation and social cooperation, and consideration of the impact of social capital on the welfare of farmers (Kuku et al., 2013), little has been done in terms direct investigation and assessment of the impact of social capital on the diffusion and success of technological innovations. This is partly due to the difficulties inherent in measuring social capital, in terms of criteria employed, and the geographical, demographic and socio-economic peculiarities of the rural context. This paper contributes to existing knowledge by exploring dimensions of social capital relevant to successful uptake of technological innovations among small-scale rural farmers in south-west Nigeria.

\section{Cooperatives, social capital and agricultural innovations}

Cooperatives, by design, fundamentally rely on social capital as well as generate it (Valentinov, 2004), and the link between cooperatives and innovation has received considerable attention in the literature. Much of this has focused on the increasingly successful model of cooperation among industrial and commercial firms on research and development, as well as adoption, of innovations (Faria et al., 2010; Marxt and Link,

Comment [t1]: If a previous version of your paper has originally been presented at a conference please complete the statement to this effect or delete if not applicable.
Comment [t2]: Author: Please provide full reference or delete from the text if not required. 
2002; Landry et al., 2002; Tether, 2002). Nevertheless the fundamental principles and features and outcomes of cooperation between firms are similar to those which are obtained with cooperative societies. It is suggested, for example, that cooperation among firms helps speed up the process of innovation as knowledge and skills are shared, risk is spread, and there is improved access to markets (Faria et al., 2010). It is also acknowledged, however, that cooperation does not always produce better outcomes, that much depends on the degree of complexity of the technological innovations, and better cooperative success is usually achieved with high-level innovations (Tether, 2002; Marxt and Link, 2002).

Various investigations have shown that membership and participation in a cooperative increase the uptake of technological innovations. A study conducted in India indicate that, in the absence of state support, farmer-to-farmer exchange in cooperatives played an important role in the diffusion of wilt-resistant pigeon pea seeds, and also helped introduce legumes into cropping systems to make them more sustainable (Parthasarathy and Chopde, 2004). Among other things, it has been suggested that information and knowledge about innovations spread more quickly within a cooperative, and this enhances confidence about innovative practices and helps facilitate a more efficient implementation of innovative practices. Cooperatives are, in effect, a community of practice with shared goals and objectives, providing unique opportunities and auspicious space for social learning and growth (Johnson, 2007). The cooperative network also provides an auspicious platform for otherwise poor farmers to organise and engage more effectively with the early stages of the design of new innovations, perhaps as intermediary organisations (Ekboir and Vera-Cruz, 2012), to facilitate information exchange and ensure that new innovations are indeed 'for the poor by the poor', relevant to the needs of the majority (Gupta, 2012). Furthermore, there is better access to credit for members of cooperatives, compared with their low-income individual counterparts, and availability of funds has a positive correlation with a higher rate of adoption of innovations (Deji, 2005; Nwakwo et al., 2009).

Some types of innovations, including most land management innovations, are better suited to groups of farmers than individual households, and here the role of cooperatives is even more significant. For example, a Family Drip Irrigation System, originally developed in Israel, requires the participation of 100 farmers working in a cooperative, and has been applied with some success both in Israel and some Africa countries (MASHAV, 2002).

Cooperatives employ several means for diffusion of innovations. Among others, technical and commercial information can be provided by means of periodic bulletins distributed among members. Talks, meetings and educational courses are also arranged for members to learn new production techniques, and cooperatives often appoint some members in their ranks to specialist teams whose responsibility is to explore and design improved methods and subsequently provide feedback and relevant advice for members (Manrique et al., 2002). However, some of these strategies for information sharing require basic levels of literacy among members, and may not be effective or appropriate for the requirements of low income, illiterate farmers in rural areas of developing countries. 


\section{Methods}

\subsection{Study locations}

A pilot study was conducted in February 2012 in selected villages of Iddo local government, in the outskirts of Ibadan City, Nigeria. The main field work was undertaken in August/September 2012. The survey locations were selected using a multi-stage purposive sampling. Thus, southwest Nigeria was chosen out of the six geopolitical zones in Nigeria. Comprising of six states, the southwest forms the bulk of pre-independence western region, and it is populated mostly by the Yoruba ethnic group. Within the southwest zone, Oyo State was selected. Oyo State is significant in the history of agricultural policies and reforms in Nigeria. Ibadan city, one of the biggest cities in Africa and the current capital city of Oyo State, was also the regional headquarters of the old Western Region. The city was the policy and administrative headquarters of the hugely successful agrarian reform of the regional government of the former Western Region, when Nigeria was still a confederacy.

\subsection{Sampling}

For this study, 4 out of 33 local governments in Oyo State were chosen. The main criteria used for multi-stage purposive sampling of survey locations were:

1 total arable land available for farming, as majority of the local governments are highly dense areas in big cities

2 intensity of agricultural activities

3 location of the states' farm settlements.

Thus, the focus was on rural areas of the state where there is more land available for agriculture and more people are engaged in farming. The farm settlements, sometimes residential with more direct government involvement, were examined along with other cooperatives to examine the peculiar character, opportunities and challenges of the system.

Altogether, 25 villages were visited and 325 farmers - both cooperative and non-cooperative members - were interviewed using structured and semi-structured interview schedules. In order to examine relationships and differences associated with gender, about every third respondent was a woman. Also, about a fifth of the respondents were farm settlers.

\subsection{Methods of analysis}

Frequency tables and descriptive statistics were used to analyse sources of information for awareness about innovations, and extension contact and adoption. Descriptive statistics were also used to analyse the contribution of social networks to innovation awareness and access, with more detailed examinations of specific strategies employed by various social networks for information sharing. Finally, we analysed the impact of cooperative membership on available external links, and the strength of linking social capital with external organisations. 
Linear regression analysis was used to examine the relationship between cooperative membership and extension contact. In addition to being identified as an important indicator of farmers' social capital, extension contact has been identified in various adoption studies for its significant influence on farmers' in-depth knowledge of, and eventual adoption of, technological innovations.

The equation for the linear regression is: $Y=a+b X$, where $X$ is the independent variable and $Y$ is the dependent variable.

\section{Results and discussions}

\subsection{Information sources and innovations}

To elicit information about the popularity and impact of information sources, six major outlets of information were selected, and respondents were to indicate the two most prominent sources from where they first became aware of the innovation [Table 1(a) and Table 1(b)].

Table 1(a) Information sources and innovations 1st response

\begin{tabular}{lcccccc}
\hline \multirow{2}{*}{ Information sources } & \multicolumn{6}{c}{ Technological innovations (in \%) } \\
\cline { 2 - 7 } & Tractor & $\begin{array}{c}\text { HY } \\
\text { maize }\end{array}$ & $\begin{array}{c}\text { HY } \\
\text { cassava }\end{array}$ & Pesticides & Fertilisers & Irrigation \\
\hline Govt. agencies & 53.1 & 46.3 & 48.5 & 43.3 & 53.1 & 19.9 \\
Fellow farmers & 41.1 & 32.2 & 37.7 & 47.9 & 39.9 & 11.3 \\
Tech sellers/others & 1.2 & 2.5 & 1.8 & 3.7 & 1.8 & 1.2 \\
Radio/TV & 2.8 & 1.8 & 1.8 & 2.1 & 1.8 & .9 \\
Newspaper/mag & 0 & .0 & .0 & .0 & .0 & .3 \\
Internet & 0 & .0 & .0 & .0 & .0 & .0 \\
\hline
\end{tabular}

Table 1(b) Information sources and innovations 2nd response

\begin{tabular}{lcccccc}
\hline \multirow{2}{*}{ Information sources } & \multicolumn{6}{c}{ Technological innovations (in \%) } \\
\cline { 2 - 7 } & Tractor & $\begin{array}{c}\text { HY } \\
\text { maize }\end{array}$ & $\begin{array}{c}\text { HY } \\
\text { cassava }\end{array}$ & Pesticides & Fertilisers & Irrigation \\
\hline Govt. agencies & 0 & .3 & 10.7 & .0 & .0 & .0 \\
Fellow farmers & 12.9 & 11.7 & 8.6 & 8.9 & 9.2 & .3 \\
Tech sellers/others & 9.5 & 9.2 & 2.8 & 12.0 & 12.0 & .6 \\
Radio/TV & 5.5 & 3.7 & .3 & 6.4 & 6.1 & .9 \\
Newspaper/mag & .3 & .6 & .0 & .3 & .3 & .0 \\
Internet & .3 & .0 & .0 & .0 & .0 & .0 \\
\hline
\end{tabular}

The sources of innovations considered here are: government agencies, fellow farmers, technology producers/others, radio and television, newspapers and magazines, and internet. 


\subsubsection{Government agencies}

Government agencies include local government councils, which are typically in closest proximity to the rural farmers, as well as various government departments at state and national levels. From the information obtained, especially as outlined in Table 1(a), government agencies appear to be the most popular outlet from which farmers first became aware of innovations. Across the range of innovations examined, government agencies account for between $43 \%$ and $53 \%$ of farmers' awareness of the innovations, except for irrigation, which stands at $20 \%$. The low figure for irrigation is consistent with generally low awareness and low adoption of irrigation among farmers, and also appears to indicate that governments, both at the local and national levels, are committing comparatively little resources to promotion of irrigation technology among farmers, especially in the Southern region. Currently, only about 3\% of cultivated land in Nigeria uses water management practices, and more than $95 \%$ of this irrigated land uses small scale irrigation schemes managed by the private sector (Takeshima et al., 2010).

\subsubsection{Fellow farmers}

The second most significant source of initial information about innovations, as Table 1(a) and Table 1(b) suggests, is through fellow farmers. This, again, has been explained in terms of close proximity (Omotayo, 2010). Indeed, farmers are closer to one another than governments, although governments typically have wider and more extensive access to information about innovations. Information exchange among farmers happens by means of informal conversation and casual observations of practices, inputs and machineries on others' farms. The spread of information is also enhanced by the comparatively high degree of trust existing among farmers, although the quality and accuracy of the exchange can sometimes be hindered by the fact of limited access farmers themselves have to information, especially in rural areas (Nwakwo et al., 2009).

\subsubsection{Other information sources}

Technology producers, for about two decades, have played significant, less acknowledged roles in the publicity of technological innovations. However, the contribution of technology sellers is limited by their business interest and alliances with big corporations. The contribution of radio and TV is lower compared with those of government agencies and fellow farmers, particularly in southwest Nigeria. The impact of television is almost negligible in rural areas, which are generally without electricity, but battery-powered transistor radios are common. It is likely, however, that some respondents may be unable to make a clear distinction between information directly disseminated by various means from government agencies, and that sponsored by governments on radio and television (Odiaka, 2010). Like newspapers and magazines, the contribution of the internet to awareness is very low.

\subsection{Awareness, extension contact and adoption of innovations}

\subsubsection{Awareness and adoption of innovations}

The figures in Table 2 indicate very high general awareness about the innovations examined, with the lowest rate being $70 \%$ for irrigation. Adoption levels for pesticides 
and fertilisers are also high at close to $90 \%$ each, whilst those of tractor, HY maize and cassava are relatively average in the 50 s and 60 s percent.

Table 2 Awareness vs. adoption of technological innovations

\begin{tabular}{lcc}
\hline Innovations & \% awareness & \% adoption \\
\hline Tractor & 100 & 68 \\
HY maize & 84 & 58 \\
HY cassava & 91 & 65 \\
Pesticides & 99 & 89 \\
Fertilisers & 100 & 87 \\
Irrigation & 70 & 6 \\
\hline
\end{tabular}

Table 2 does not portray any clear correlation between awareness and adoption, however, as several respondents who are 'aware' of the innovations could also have had more in-depth technical information about the innovations.

The high level of awareness and adoption for pesticides and fertilisers may be linked to the fact that they are associated with lower levels of technical complexity and risks. Also in addition to the comparatively cheaper cost of pesticides, it appears more efforts have been focused on the two innovations in terms of publicity and distribution by sellers and government agencies (Okoedo-Okojie and Aphunu, 2011; Tijani and Sofoluwe, 2012).

Figure 1 Extension contact and adoption (see online version for colours)

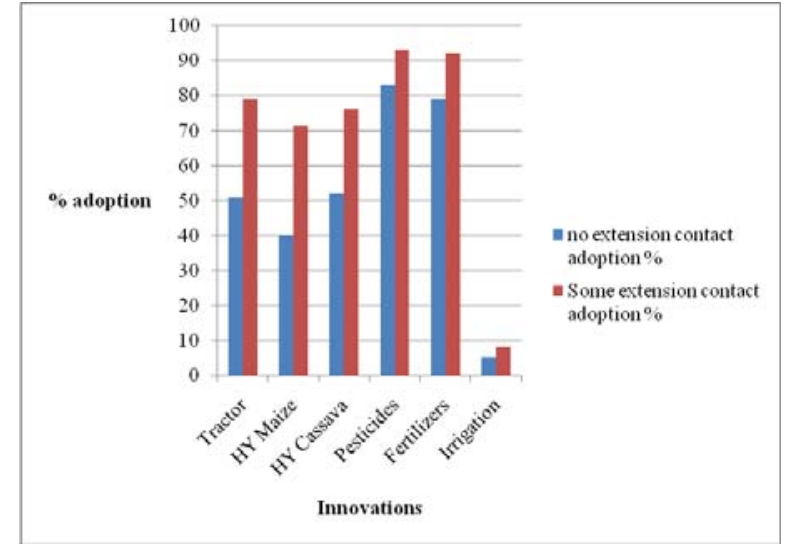

\subsubsection{Extension contact and adoption}

From the results summarised in Figure 1, extension contact appears to have significant impact on farmers' adoption of innovations. In general, farmers who have had some level of contact with extension workers have higher rates of adoption than those who have had no contact. The adoption rates for the two categories of farmers are closer for fertiliser and pesticides, perhaps on account of lower technical complexity and risk associated with 
the two innovations, but for high yield maize, tractor and cassava, the adoption rates are much higher for farmers who have had contact with extension workers. With tractor, for example, there is an adoption rate of $79 \%$ for farmers with extension contact, compared with $51 \%$ for those who have had no extension contact.

The frequency of farmers' contact with extension workers represent an important measure of in-depth information accessed by farmers, and this is in turn related to the interest and evaluation stage of the innovation adoption life-cycle. Among other things, extension workers organise seminars where details of the innovations are explained to farmers with regard to technical features, methods of operation/application and maintenance, as well as details about potential benefits. On-field demonstrations are also given to reinforce explanations provided in seminars and lectures. As other studies have shown, these physical interactions with extension agents provide farmers with unique opportunities to clarify otherwise superficial information and more thoroughly evaluate the innovations, before full-scale adoption (Akinnagbe and Ajayi, 2010).

The results outlined in Figure 2 provide further details about the impact of contact with extension workers. As Figure 2 indicates, farmers who meet once or twice a year with extension workers have, by and large, similar rates of adoption. For example, farmers who meet twice a year with extension workers have $19 \%$ adoption rate for HY cassava, compared with $17 \%$ rate for those who meet once a year. Conversely, the adoption rate for those who meet more frequently/once a month, is $32 \%$. A similar pattern is repeated throughout for the other innovations, although there is a fairly big gap on adoption of irrigation for those who meet once or twice a year with extension workers.

Figure 2 Frequency of extension contact (see online version for colours)

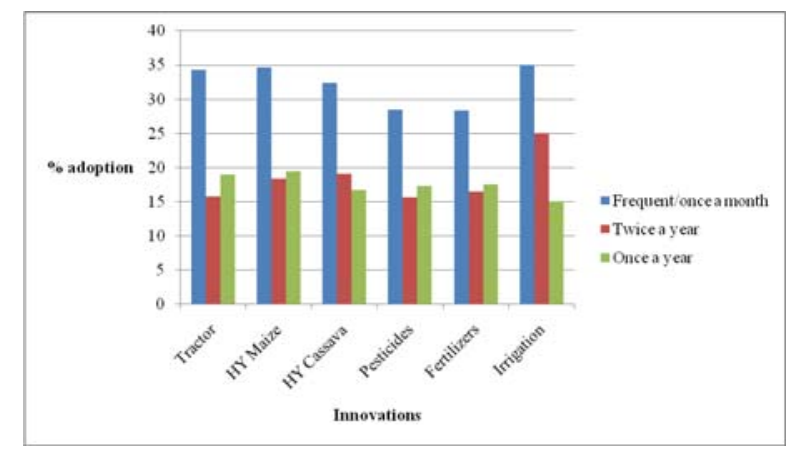

Technological innovations are in a continual state of development, and, especially for agricultural innovations, local conditions play considerable part on how, and to what extent farmers can overcome risks and gain optimum benefit from application of innovations. Thus, regular contact with extension workers afford the opportunity for farmers to discuss new concerns and challenges arising from trial applications of new innovations, as well as obtain new ideas on how best to apply the innovations (Ofuoku, 2012). This ongoing interaction can be particularly important in the evaluation stage of the innovation adoption lifecycle, as discussed in the foregoing.

It is observed that extension agencies are not the only instrument of continuing education of farmers on innovations. Technology sellers and NGOs sometimes undertake 
the role of agricultural extension, sometimes in remote areas not covered by extension workers, and sometimes simply to complement or reinforce the work of extension agencies. This implies that farmers who do not have regular contact with extension workers can benefit from other sources of information where they can discuss and clarify ongoing concerns regarding trials of innovations on their farms. However, partly because these NGOs are often involved in a wide variety of developmental projects, they typically do not have the specialised trainings and more extensive range of technical support and information provided by extension agents.

\subsubsection{Extension contact and use intensities}

Analysis of use intensity provide important additional information on farmers overall adoption behaviour. High use intensity is, among other things, a measure of farmers' confidence in the adopted innovation, and their versatility in terms of effective operation and maintenance for optimum benefit. This confidence and versatility is usually connected with the level of technical information accessed by farmers, and this is generally provided by extension agencies. Figure 3 provides a summary of data on farmers who have applied respective innovations on more than $70 \%$ of their farm holdings in land areas.

Figure 3 Extension contact and use intensities (see online version for colours)

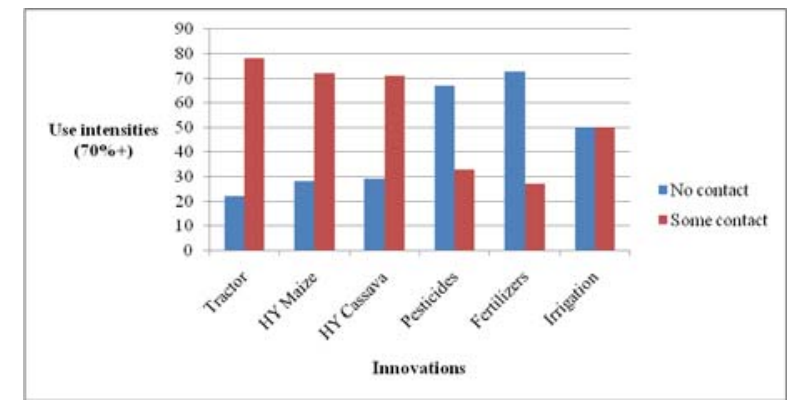

For pesticides and fertilisers, the results indicate that contact with extension workers does not make a difference on farmers' use intensities, with roughly $70 \%$ of farmers with no extension contact applying pesticides and fertilisers on more than $70 \%$ of their farm holdings. As discussed in the previous sections, this may have to do with the relatively low technical complexity associated with the two innovations, as well as easier access in terms of distribution. However, for tractor, HY maize and tractor combine, more than $70 \%$ of those who have applied the innovations on most of their holdings are farmers who have had some extension contact.

\subsection{Cooperative membership and extension service}

The result of regression analysis of cooperative membership and contact with extension workers, shown in Table 3, indicates that cooperative membership exerts significant impact on frequency of contact with extension workers. With a p-value of 0.000 , the 
B-value indicate that farmers who are cooperative members are 58 times more likely to have contact with extension workers, compared with farmers who are non-cooperative members.

Table 3 Cooperative membership and extension contact

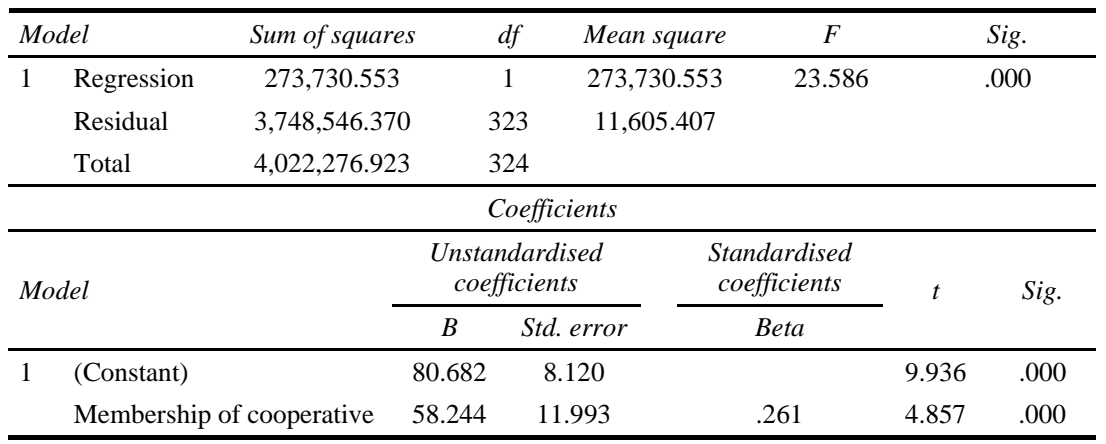

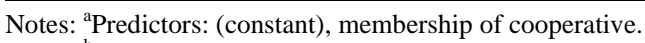

${ }^{\mathrm{b}}$ Dependent variable: frequency of contact with extension workers.

The cooperative structure provides a platform for groups of farmers to interact and engage regularly with extension workers. Extension agencies always prefer to work with groups, rather than individual farmers, for more efficient deployment of their technical expertise and support Again, because cooperative farmers typically have a longer history of established association with each other, and with extension workers, they are generally in a better position to communicate ongoing concerns and technical difficulties they have struggled with over longer periods of time, and thus participate in a two-way process of feedback and sharing information and experiences that ultimately contribute significantly to better design and applications of adopted innovations (Akinnagbe and Ajayi, 2010; Prakash, 2005).

Also, cooperatives farmers can benefit more readily from on-field demonstrations of techniques and processes in, say, a farmland jointly owned or arranged for that purpose by members, as well as commit more easily to any financial contributions that can make such demonstrations more helpful. The formal leadership structure of cooperatives also provides a regular and potentially more effective channel of communication between cooperative farmers and extension workers, especially with regard to emergency needs and inquiries that may arise outside of formal meeting times.

\subsection{Technology characteristics}

The technology characteristic examined in this study is ease of use, and farmers who have adopted or trialled the innovation were asked to assess each of the innovations in terms of ease of use. The evaluation is thus essentially subjective, a reflection of individual farmers' perception, which may in turn be connected with experience and length of usage, and level of education and amount of technical information available to farmers. This perceived ease of use has been identified by diffusion researchers as an important factor shaping farmers attitudes towards innovations, and influencing continuity of use (Ajzen and Fishbein, 1980; Davis, 1989; Tenech, 1998). 
As Figure 4 shows, the vast majority of farmers who have adopted or tried most of the innovations consider them easy to use. The only exception is irrigation, which about $30 \%$ of respondents consider a bit difficult or very difficult to use. This may be connected with the fact that there is very little awareness, especially in south-west Nigeria, about irrigation technology, and very little of government resources have been committed to promotion of irrigation technology among small scale farmers in southwest Nigeria.

Figure 4 Innovations and perceived ease of use (see online version for colours)

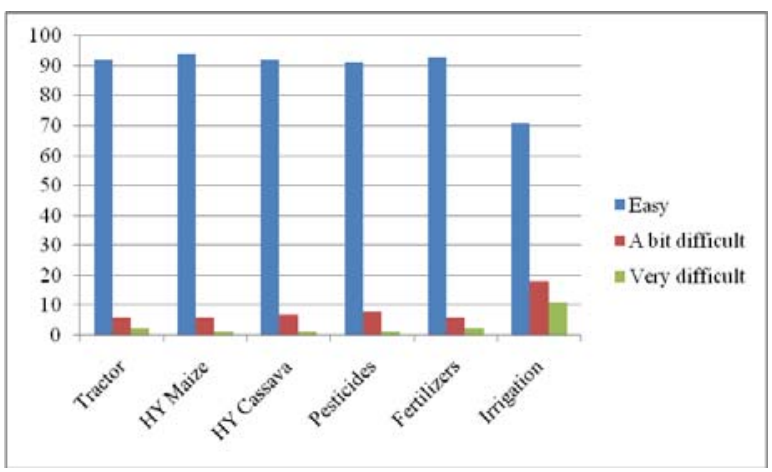

\subsection{Social capital and network strength}

The foregoing sections have focused primarily on analysis and discussion of various factors and indicators contributing to cooperative farmers' access to in-depth technical information about innovations, beyond the level of general awareness that the innovations exists. These deeper levels of information are especially significant in a discussion of the interest and evaluation stage of an innovation. However, it is possible to altogether neglect, or not give adequate attention to, other facilities and opportunities available to farmers, whether or not they belong to cooperatives, in terms of their information access and capacity to gain optimum benefit from adoption of technological innovation. It is also important to compare the effectiveness of farmers' cooperatives with other platforms of social organisation of farmers.

Some researchers have distinguished between intra family and extra family types of social capital, the former based on relationships between family members and benefits, in terms of human and financial capital, that can be accrued from such relationships. On the other hand, extra family social capital refers to other relationships and network, of different types, within the wider community, which individuals and households can harness to surmount adverse challenges and difficulties (Astone and McLanahan 1991; Liverpool-Tasie et a.l, 2011). Thus, this section focuses on the contributions various sources and forms of social capital to information, access and optimum adoption of innovations. In addition to farmers' cooperatives, other sources of social capital examined are

1 family, friends and relations

2 religious organisations 
3 other cooperatives.

\subsubsection{Contribution to awareness and access}

Four categories of social network are examined, and most farmers belong to two or more of the categories. The information sought about the contribution of the social networks to awareness and access is related to, yet distinct from, the data obtained in Section 4.1 above. Here, the primary focus is not on the source of information, but on the impact of the various networks in getting the information, and accessing the innovation. For example, the social network, say friends, may be the instrument through which the farmers are linked with or directed to an information source, say a government agency.

Table 4 Contribution of social network to innovation awareness and access

\begin{tabular}{lcc}
\hline Categories & Contribution to awareness (\%) & Contribution to access (\%) \\
\hline Family and friends & 46.9 & 47.9 \\
Religious organisation & 5.5 & 2.8 \\
Farmers' cooperatives & 34.4 & 33.1 \\
Other cooperatives & 4.9 & 5.2 \\
\hline
\end{tabular}

On the question of which network is the best contributor to awareness of technological innovations, about $47 \%$ of the respondents indicate family and friends, whilst $34 \%$ indicated farmers' cooperatives (Table 4). The highest percentage for family and friends can be explained in terms of proximity. Family and friends typically meet and interact with greater frequency than other categories, and their levels of trust are higher, all contributing to ready exchange of information (Astone and McLanahan 1991). The contribution of farmers' cooperatives, with the 2nd highest percentage, can also be accounted for in terms of the formality and regularity of the cooperative arrangement, as well as the specificity of the goals and objectives geared to promoting farmers' productivity and profit. Religious organisation hold a strong potential, in terms of frequency of meetings and potential trust, but the impact is quite low at 5.5\%, probably on account of the fact that such organisations are usually more engaged with spiritual well-being of members, often to the exclusion of any economic issues, especially in the Nigerian context.

Regarding contribution to innovation access, the results are similar to the ones obtained for contribution to awareness, with the highest value of $48 \%$ going to contribution by family and friends, and 33\% for farmers' cooperatives. Non-cooperative farmers rely almost exclusively on family and friends for access and procurement of innovative farm inputs, but it appears some of the cooperative farmers also seem to value the contribution of family and friends more when it comes to getting access to innovations. Association with family and friends do not entail regular costs in terms of membership dues and other contributions. For example, a friend or family members, especially one with a means of transport, may offer to buy, alongside his own procurement, for a fellow friend, at no additional cost in terms of transporting the goods. Conversely, however, the cooperative arrangement brings the guarantee of regular structure and commitment, as well as better economy of scale both for the cost of inputs and cost of transportation. 


\subsubsection{Strategies for information sharing}

In order to examine further details regarding the apparent gap between superficial awareness and in-depth knowledge and technical information, respondents are asked about the means by which they obtain information about innovation, as well as the means by which their preferred network influences their decisions to adopt innovations.

Figure 5 Network strategies and models for sharing information (see online version for colours)

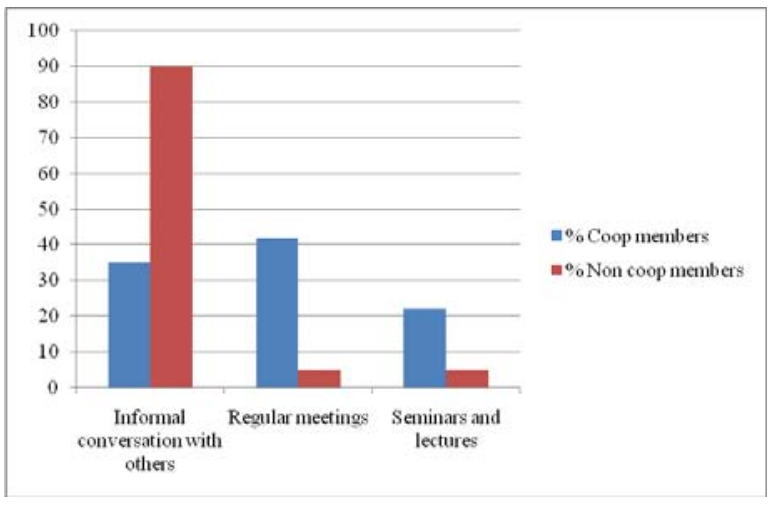

The results of the cross tabulation analysis, shown in Figure 5, indicates, as expected that non-cooperative members rely heavily on informal conversation as the means of getting information about technological innovations, with very few of them benefiting from regular meetings or seminars and lectures. For cooperative farmers, informal conversation also play an important role, but regular meeting is the principal method of sharing and exchanging information, and seminars and lectures play significant roles.

The advantage of informal conversation is that it is cheap and ready in terms of access and availability. A farmer typically meets a fellow farmer in the course of the working day, and there is ample opportunity in such spontaneous encounters to exchange and share useful information. However, in terms of the quality and depth of information accessible, regular meetings and seminars/lectures present distinct advantages. First, a regular meeting brings together farmers who may otherwise not be acquainted with each other enough for informal conversation, and in that sense is a bridge of social distance. Also, the meeting place is a platform to bring many farmers together at once, and it is effectively a melting pot where different farmers can share ideas and experiences that have worked, as well as difficulties they have dealt or are dealing with. Thus, there is more information available than one-to-one informal exchange with individual farmers.

Seminars and lectures are important as instruments of obtaining in-depth technical information from experts. Experts can be a fellow farmer, but usually these seminars and lectures are facilitated by invited experts from extension agencies and other external bodies. From Figure 5, it can be seen that very few non-cooperative members benefit from seminars and lectures because these are often arranged by cooperatives and other farmer groups, who have established history of formal contact and interaction with those external bodies (Akinnagbe and Ajayi, 2010; Ofuoku, 2012). Also, where cost is involved 
in terms of paying for the services or logistical costs of invited expert facilitators, cooperatives are in a stronger position to mobilise contributions from members.

\subsubsection{Network influence on adoption decisions}

Respondents were also asked about the most important factor, from their preferred network, influencing their final adoption decisions. Information is important, but not necessarily decisive, regarding farmers final decision to adopt technological innovations. Three key factors were highlighted in this study: verbal affirmation on the value of the innovation by those who have used it; formal field trials and demonstrations facilitated by the network; and informal observation of application or impact of the innovations on others' farms.

Figure 6 shows that verbal affirmation of the value of innovations by others constitutes an important factor in farmers' adoption decision, both for cooperative and non-cooperative members, representing $63 \%$ for cooperative members, and $55 \%$ for non-cooperative members. This affirmation is likely to occur in the course of informal interactions and regular meetings outlined in the foregoing.

Figure 6 Network influence on adoption decisions (see online version for colours)

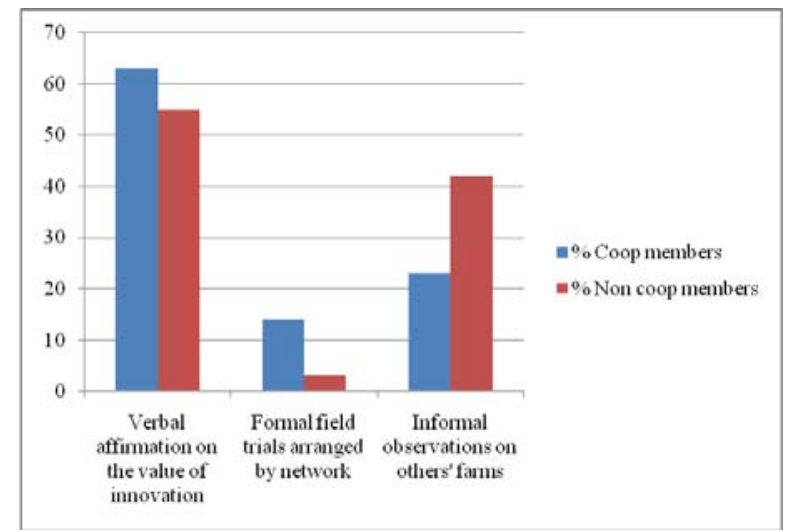

This also indicates the level of trust existing between farmers, and this trust is an important index of social capital. Significantly, $42 \%$ of non-cooperative members and $23 \%$ of cooperative members also cited informal observation on others' farms as the decisive factor in their decision to adopt. This is perhaps in response to the need to gain a more practical understanding of how to apply the innovations correctly, beyond general information about the innovation. Also, farm observations is an opportunity to physically evaluate and compare the quality of yield with innovative inputs, compared with traditional methods and inputs applied either on the observed, or observers' farm.

As Figure 6 also shows, only 3\% of non-cooperative members, as against 14\% of cooperative members, benefit from formal field demonstrations, which are usually facilitated by experts from external agencies like extension workers, research institutes and technology sellers. As observed in the foregoing, cooperatives and organised farmers' groups enjoy closer and established interactions with these external 
organisations. In terms of benefits, formal field trials are similar to informal observations of fellow farmers' farms. However, the presence of technical experts is a significant advantage in formal field trials, in that farmers can explore more in terms of technical details, and obtain support on newer and more effective ways of dealing with difficult challenges faced on application of the innovations. In spite of the potential advantages of formal field trials, it appears that comparatively little of it is available to, or arranged by, either category of farmers.

\subsection{Networks and external links}

Linking social capital has been defined in terms of connections with people in power, with either or both financial and political influence, as well vertical connections to formal institutions like governments and NGOs (Woolcock and Sweetser, 2002; Woolcock, 2001; Mayoux, 2001). The level of connection established by a network with important external bodies and organisations for the benefit of the network's members is a significant measure of the strength of that network. This investigation examined four main categories of external links, potentially valuable for farmers' access to technological innovations: government officials, technical experts/extension workers, finance agencies, and local leaders. Respondents were asked to identify which of the external links is the most effective for access and use of innovations.

The results shown in Figure 7 indicate that both cooperative (52\%) and non-cooperative (41\%) farmers consider government officials as the most important external link for their access to, and use of, innovations.

Figure 7 Farmers' ranking of external links (see online version for colours)

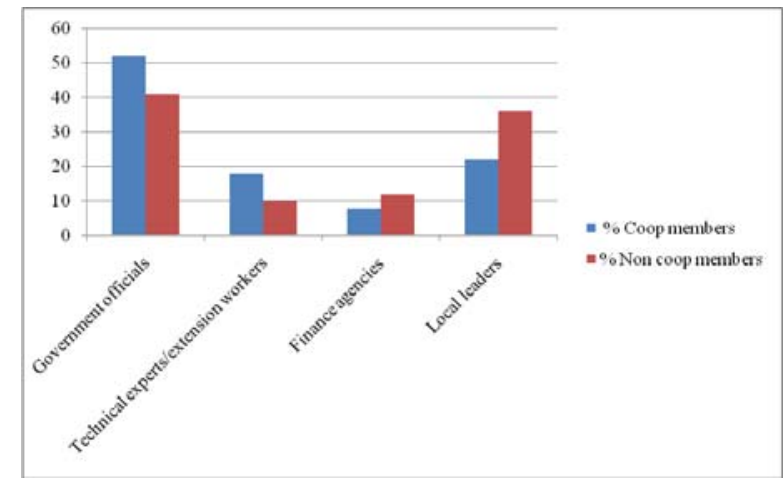

This appears to be a reflection of expectations as well as current impact of governments. Farmers typically express frustration that government is not doing enough to support their agricultural enterprise, yet there is also an acknowledgment that the government, at various levels, is the current biggest source of external support enjoyed by farmers, with respect to access to innovations. For example, subsidised inputs and equipment are almost always at the behest of governments, and the distribution of this is usually controlled by officials at the relevant government ministries. 
Local leaders are next in rank of valuable external links, perhaps because they are recognised as very effective intermediaries between local farmers and government officials, NGOs and other external organisations with services or products that can be of value to farmers, and with whom it will be difficult to make direct contact. Cooperative members are stronger with regard to their ability to link directly with governments and other external bodies, but, as Figure 7 shows, non-cooperative members rely more on the influence and intervention of local leaders. Extension workers are not ranked so highly perhaps due to the fact that most of the extension service accessed by farmers is provided by government departments. Similarly, it is almost impossible for a Nigerian small scale farmer to secure funds directly from banks and other finance agencies, without going through government or local leaders.

On the question of which of the networks is most effective in establishing links with external bodies identified in Figure 8, the majority of the cooperative members, as expected, identified the cooperative society. Conversely, more than $70 \%$ of non-cooperative members identified family and friends. Significantly, about $40 \%$ of cooperative members also identified family and friends as the most effective network for linking up with important external bodies. It is possible that some of the friendships are also forged or strengthened in the cooperative, but the considerably high impact of family and friends may be connected with dynamics of the Nigerian political environment, in which political connection and contact with government officials are often secured through long and interwoven networks of family and friends, from the local level all the way to the state and national level. This does not necessarily mean that cooperatives are weaker than the family network, say, considering the fact that non-cooperative members can only accurately rate what they have experienced regarding the impact and value of the family/friends network. It is also instructive that $20 \%$ of non-cooperative farmers, along with $55 \%$ of cooperative members, identified the cooperative as the most effective network in linking up with external bodies.

Figure 8

Comment [t3]: Author: Please provide the missing figure.

Comment [t4]: Author: Please provide the figure caption. 
Table 5 Comparing social capital of cooperative and non-cooperative farmers

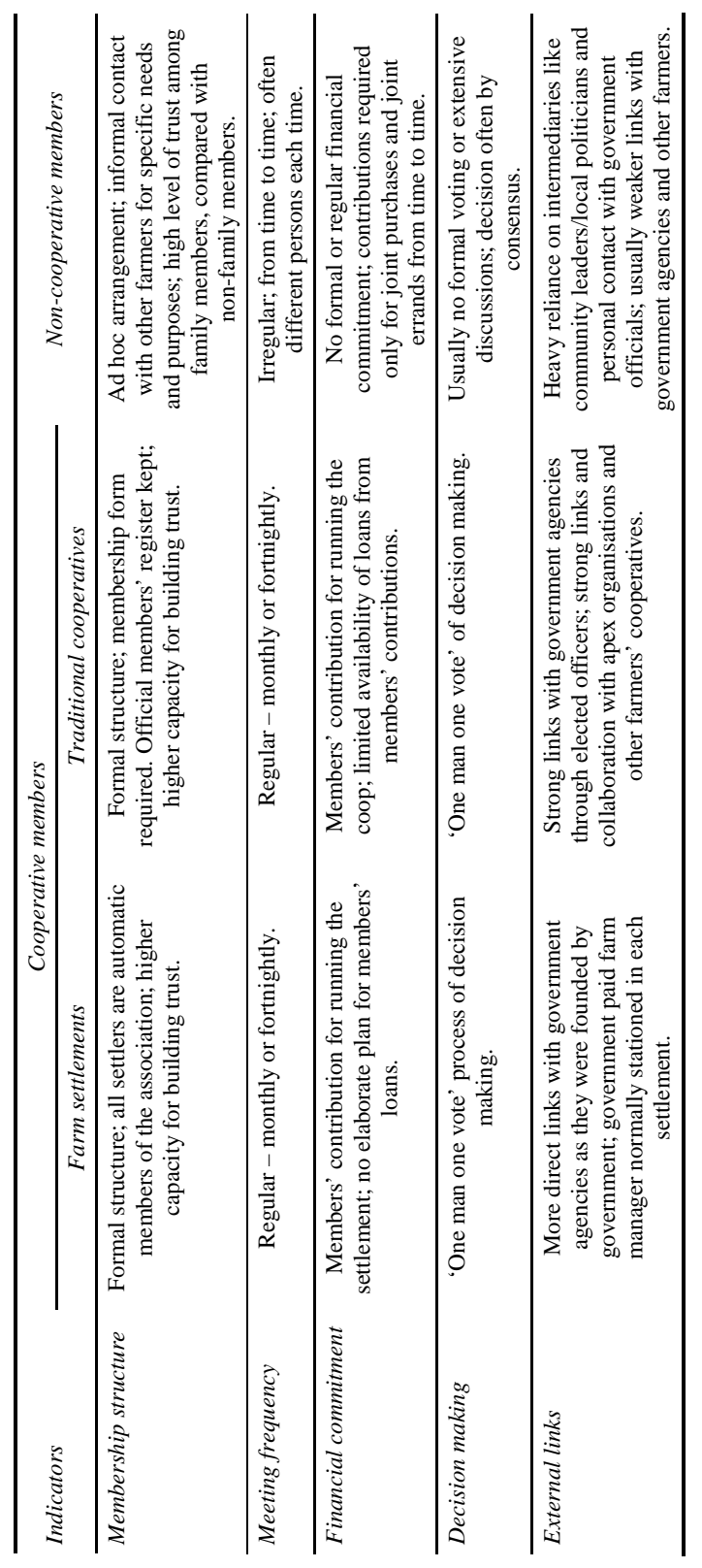


The very low level of effectiveness ascribed to religious organisations in this study is surprising, considering the fact that religion play increasingly prominent roles in Nigeria's political process, as well as individual lives. It would appear that religious organisations have not harnessed their considerable linking social capital to support farmers by connecting them with external organisations that can be of considerable value for innovation access. There could be logistical and practical difficulties arising from the facts that these religious organisations are highly diversified regarding the vocations of their members, but the significant influence of religious organisation appears to be severely under-utilised for the benefit of farmers. Table 5 provides a summary of comparative social capital of cooperative and non-cooperative farmers.

\section{Conclusions}

This study indicates that the main sources of initial information for farmers are government agencies and fellow farmers, but extension agencies bring more significant impetus in terms of moving the farmers from a point of mere awareness to evaluation and trial stages in the adoption life-cycle. With regard to access to extension services, cooperatives and other farmer groups are typically in a stronger position, in terms of the logistics of mobilising members, arranging dates and venues, as well as efficiency of outreach from the standpoint of extension agencies, which are severely limited in terms of field workers.

In general, the cooperative arrangement appear to be a more effective platform for generating and maintaining social capital, which in turn helps to facilitate more effective access to, and exchange of information for farmers, as well as link up with external organisations that are of importance to farmers for access and beneficial use of innovations. This is particularly important in the Nigeria context, as a recent study previous observation that institutional weaknesses and failures are responsible for the under-development of Nigeria's agriculture, compared with significant progress enjoyed by countries like Malaysia and Brazil, which were in similar positions, economically and geographically, 50 years ago (Adebowale, 2012). Revived cooperatives, operating under a new business oriented model, can be at the heart of new policy drives for integrated institutional reform for successful agricultural innovation system in Nigeria.

The results of this investigation have also highlighted, but not sufficiently explored, considerable underperformance of the cooperative networks, especially with regard to support accessible to farmers to mitigate and alleviate various challenges and difficulties associated with adoption and application of innovations. In addition, the contributions of governments at various levels appear to be below the expectations of farmers, but there are no adequate quantitative data to explore this in sufficient detail. Thus, a future study will draw on opinions of farmers and other key stakeholders to examine if, and to what extent, institutional factors like government policies, markets, and credit institutions affect successful uptake of technological innovations.

\section{References}

Adebowale, B.O.A. (2012) 'Innovation policies, institutions and performance: why Malaysia overtook Nigeria in the oil palm industry', Int. J. Technological Learning, Innovation and Development, Vol. 5, Nos. 1/2, pp.126-157. 
Ajzen, I. and Fishbein, M. (1980) Understanding Attitudes and Predicting Social Behavior, Princeton-Hall, Englewood Cliffs, NJ.

Akinnagbe, A. and Ajayi, A. (2010) 'Challenges of farmer-led extension approaches in Nigeria', World Journal of Agricultural Sciences, Vol. 6, pp.353-359.

Aldridge, S., Halpern, D. and Fitzpatrick, S. (2002) Social Capital - A Discussion Paper, Performance and Innovation Unit, Admiralty Arch., London.

Astone, N. and McLanahan, S. (1991) 'Family structure, parental practices and high school completion', American Sociological Review, Vol. 56, pp.309-320.

Bourdieu, P. and Wacquant, L.P.D. (1992) 'Interest, habitus, rationality', An Invitation to Reflexive Sociology, p.119, University of Chicago Press, Chicago.

Davis, F. (1989) 'Perceived usefulness, perceived ease of use, and user acceptance of information technology', MIS Quarterly, Vol. 13, pp.319-340.

Deji, O. (2005) 'Membership of co-operative societies and adoption behaviour of women farmers: implication for rural development', J. Soc. Sci., Vol. 10, No. 2, pp.145-147.

Deroian, F. (2002) 'Formation of social networks and diffusion of innovations', Research Policy, Vol. 31, pp.835-846.

Ekboir, J.M. and Vera-Cruz, A.O. (2012) 'Intermediary organisations to foster the agricultural system of innovation: the Mexican Produce Foundation', Int. J. Technological Learning, Innovation and Development, Vol. 5, Nos. 1/2, pp.111-125.

Faria, P.D., Lima, F. and Santos, R. (2010) 'Co-operation in innovation activities: the importance of partners', Research Policy, Vol. 39, pp.1082-1092.

Gupta, A.K. (2012) 'Innovation for the poor by the poor', Int. J. Technological Learning, Innovation and Development, Vol. 5, Nos. 1/2, pp.28-39.

Johnson, H. (2007) 'Communities of practice and international development', Progress in Development Studies, Vol. 7, No. 4, pp.277-290.

Landry, R., Amara, N. and Lamari, M. (2002) 'Does social capital determine innovation? To what extent?’, Technological Forecasting and Social Change, Vol. 69, pp.681-701.

Liverpool-Tasie, L.S., Kuku, O. and Ajibola, A. (2011) A Review of Literature on Agricultural Productivity, Social Capital and Food Security in Nigeria, International Food Policy Research Institute, Abuja.

Manrique, E., Marcén, F., Maza, M. and Olaizola, A. (2002) 'Commercial strategies and horizontal diffusiono of innovations in a sheep farming co-operative enterprise: the case of Cane Aragon', CIHEAM - Options Mediterraneennes, pp.105-108.

Marxt, C. and Link, P. (2002) 'Success factors for cooperative ventures in innovation and production systems', Int. J. Production Economics, Vol. 77, pp.219-229.

MASHAV (2002) Techno-Agriculture Innovation for Poverty Alleviation - Senegal \& West Africa, Johannesburg, South Africa, SN.

Mayoux, L. (2001) 'Talking the downside: social capital, women's empowerment and micro-finance in Cameroon', Development and Change, Vol. 32, pp.435-464.

Nwakwo, U.M., Peters, K.J. and Bolkemann, W. (2009) 'Can cooperative membership and participation affect adoption decisions? Issues for sustainable biotechnology dissemination', AgroBio Forum, Vol. 12, pp.437-451.

Odiaka, E.C. (2010) 'Differential mass media use among rice farmers in Nigeria: evidence from Benue State', J. Communication, Vol. 1, No. 1, pp.33-36.

Ofuoku, A. (2012) 'Influence of extension agents and farmers' communication factors on the effectiveness of poultry technology messages’, Tropical Agricultural Research \& Extension, Vol. 15, No. 1, pp.14-23.

Okoedo-Okojie, D.U. and Aphunu, A. (2011) 'Assessment of farmers' attitude towards use of chemical fertlizers in the Northern Agricultural Zone of Delta State, Nigeria', Archives of Applied Science Research, Vol. 3, No. 1, pp.363-369.
Comment [t5]: Author: Please provide the issue number.

Comment [t6]: Author: Please provide the issue number.

Comment [t7]: Author: Please provide the issue number.

Comment [t8]: Author: Please provide the issue number.

Comment [t9]: Author: Please provide the issue number.

Comment [t10]: Author: Please provide the issue number.

Comment [t11]: Author: Please provide the issue number.

Comment [t12]: Author: Please provide the issue number.

Comment [t13]: Author: Please provide the issue number. 
Omotayo, A.M. (2010) The Nigerian Farmer and the Elusive Crown, University of Agriculture, Abeokuta, Abeokuta.

Parthasarathy, D. and Chopde, V. (2004) Building Social Capital: Collective Action, Adoption of Agricultural Innovation and Poverty Reduction in the Indian Semi-Arid Tropics, Indian Institute of Technology, Bombay.

Prakash, D. (2005) Agricultural Extension Services Provided By Cooperatives, IFFCO Foundation, New Delhi.

Rogers, E.M. (1995) Diffusion of Innovations, 4th ed., Free Press, New York.

Takeshima, H., Salau, S., Adeoti, A. and Okoli, S. (2010) Economics of Farmers' Demands for Private Irrigation in Nigeria, International Food Policy Research Institute, Abuja.

Tenech, T. (1998) 'Using perceived ease of use and perceived usefulness to predict acceptance of the World Wide Web', Computer Networks and ISDN Systems, Vol. 30, pp.629-630.

Tether, B.S. (2002) 'Who cooperates for innovation, and why', Research Policy, Vol. 31, pp.947-967.

Tijani, A.A. and Sofoluwe, N.A. (2012) 'Factors determining the extent of pesticide use in Nigerian farms', Journal of Agricultural Economics and Development, Vol. 1, No. 1, pp.1-9.

Valente, T.W. and Davis, R.L. (1999) 'Accelerating the diffusion of innovations using opinion leaders', The ANNALs of the American Academy of Political and Social Science, Vol. 566, No. 1 , pp.55-67.

Valentinov, V. (2004) 'Toward a social capital theory of cooperative organisation', Journal of Cooperative Studies, Vol. 37, pp.5-20.

Woolcock, M. (2001) 'The place of social capital in understanding social and economic outcomes', ISUMA Canadian Journal of Policy Research, Vol. 2, No. 1, pp.11-17.

Woolcock, M. and Sweetser, A.T. (2002) 'Bright ideas: social capital - the bonds that connect', Asian Development Bank Review, Vol. 34, No. 2, pp.26-27.

Comment [t14]: Author: Please provide the issue number.

Comment [t15]: Author: Please provide the issue number.

Comment [t16]: Author: Please provide the issue number. 